\title{
A Unique Case of Recurrent Upper Gastrointestinal Bleeding Caused by Two Metachronous Dieulafoy's Lesions: The Role of EUS Evaluation
}

\author{
Mariana Brito ${ }^{a, b}$ Gonçalo Nunes ${ }^{a, b}$ Pedro Pinto Marques ${ }^{a}$ Manuela Canhoto ${ }^{a}$ \\ Ana Luísa Proençac Jorge Fonseca ${ }^{a}$ b \\ ${ }^{a}$ Gastroenterology Department, Hospital Garcia de Orta, Almada, Portugal; b PaMNEC - Grupo de Patologia Médica, \\ Nutrição e Exercício Clínico, CiiEM, Centro de investigação interdisciplinar Egas Moniz, Monte da Caparica, Portugal; \\ 'Radiology Department, Hospital Curry Cabral, Centro Hospitalar Lisboa Central, Lisbon, Portugal
}

\section{Keywords}

Gastrointestinal bleeding - Dieulafoy's lesion - Endoscopic ultrasonography · Endoscopic hemostasis · Interventional radiology

\section{Abstract}

Introduction: Dieulafoy's lesion (DL) is a rare but important cause of acute, severe, life-threatening, and recurrent upper gastrointestinal bleeding (UGIB). It is frequently difficult to diagnose DL with upper GI endoscopy (UGIE), and endoscopic ultrasonography (EUS) may be valuable. There are only 2 reported bleeding cases caused by two synchronous DL but no reported cases of two metachronous DL. Case Report: A 28-year-old healthy male presented with acute severe UGIB. UGIE was inconclusive. Systematic EUS mapping identified a gastric DL. After several attempts of EUS-guided hemostasis, DL was marked using a through-the-scope clip and the patient underwent successful transcatheter arterial embolization (TAE). Three years later, a new severe UGIB episode was caused by a second gastric DL in a different location, which was identified and marked by EUS and further successfully treated through TAE. The patient maintained follow-up without evidence of further bleeding. Discussion/
Conclusion: The authors report a unique case of severe, recurrent UGIB caused by two metachronous gastric DL lesions. The importance of systematic EUS scanning for diagnosis, treatment, and follow-up of DL is emphasized, as well as the potential influence in the outcome of other techniques like angiographic embolization.

(c) 2020 Sociedade Portuguesa de Gastrenterologia Published by S. Karger AG, Basel

\section{Um caso único de hemorragia digestiva alta recorrente causada por duas lesões de Dieulafoy metácronas: a importância da avaliação por ecoendoscopia}

\section{Palavras Chave}

Hemorragia digestiva · Lesão de Dieulafoy · Ecoendoscopia $\cdot$ Hemostase endoscópica $\cdot$ Radiologia de intervenção

\section{Resumo}

Introdução: a lesão de Dieulafoy (LD) é uma causa rara de hemorragia digestiva alta (HDA), podendo causar hemor- karger@karger.com www.karger.com/pjg

Karger $\stackrel{\text { ' }}{5}$

BOPEN ACCESS
(C) 2020 Sociedade Portuguesa de Gastrenterologia Published by S. Karger AG, Basel

This article is licensed under the Creative Commons AttributionNonCommercial-NoDerivatives 4.0 International License (CC BYNC-ND) (http://www.karger.com/Services/OpenAccessLicense). Usage and distribution for commercial purposes as well as any distribution of modified material requires written permission.
Mariana Brito

Gastroenterology Department

Hospital Garcia de Orta, Av. Torrado da Silva

PT-2805-267 Almada (Portugal)

marianasbrito076@gmail.com 
ragia grave e recorrente. Diagnosticar esta lesão através da endoscopia digestiva alta (EDA) pode ser um desafio e a ecoendoscopia (EUS) é uma ferramenta muito útil. Há apenas dois casos reportados de hemorragia digestiva por duas LD síncronas, mas não há casos descritos de doentes com duas HDA por LD metácronas. Caso Clínico: homem de 28 anos, saudável, admitido por HDA grave, EDA inconclusiva. Mapeamento gástrico sistemático por EUS identificou LD gástrica. Várias tentativas ineficazes de hemostase endoscópica e guiada por EUS. Marcação da LD com clip guiada por EUS e referenciação para embolização arterial (EA), bem-sucedida. Três anos depois, nova HDA grave devido a uma segunda LD gástrica, em topografia diferente, diagnosticada e marcada com clip por EUS, tratada com EA. Até à data sem recidiva. Discussão/Conclusão: relatamos um caso único de HDA grave recorrente, causada por duas LD gástricas metácronas. Salienta-se a importância de uma avaliação sistemática por EUS no diagnóstico destas lesões. Salientamos o papel desta técnica no diagnóstico e tratamento das LD e possibilidade de articulação com outras técnicas, nomeadamente a EA.

(c) 2020 Sociedade Portuguesa de Gastrenterologia Published by S. Karger AG, Basel

\section{Introduction}

Dieulafoy's lesions (DL) are relatively rare, being responsible for approximately $1.5 \%$ of acute upper gastrointestinal bleeding (UGIB) and for nearly $3.5 \%$ of jejunoileal bleeding [1-3]. These lesions are responsible for severe acute UGIB episodes, which are usually life-threatening, recurrent, and very often present a major diagnostic challenge [4].

Upper GI endoscopy (UGIE) is the usual tool for gastric DL diagnosis, although it can fail in up to $30 \%$ of cases [5], especially in the absence of active bleeding. In these cases, endoscopic ultrasonography (EUS) can be useful to confirm the diagnosis $[6,7]$. The therapeutic role of EUS in managing GI bleeding when conventional endoscopic therapies fail has rapidly evolved [8]. EUS-guided therapies include injection of vasoconstrictor or sclerosing drugs, coil embolization, and subepithelial tattoo for posterior endoscopic band ligation [9]. Furthermore, EUS can be used to guide alternative endoscopic or radiologic procedures [9] and to confirm therapeutic success by demonstrating absent blood flow after therapy [6].

The authors report a unique case of recurrent UGIB due to two metachronous gastric DL in the same patient and emphasize the important role of EUS in the diagnosis, treatment, and follow-up of these lesions, as well as its usefulness when associated with other techniques.

\section{Case Presentation}

A 28-year-old male was admitted in the emergency room with acute UGIB presenting with hematemesis and syncope. There was no remarkable past medical history and no features of chronic liver disease on physical examination. The patient denied alcohol abuse, smoking habits, and chronic or recent medication intake, namely nonsteroidal anti-inflammatory drugs. At admission, he was hypotensive and presented blood in the nasogastric tube, requiring transient vasopressor support, and was admitted in the Intensive Care Unit. The UGIE revealed fresh blood and a giant clot in the stomach covering the gastric body and fundus, as well as blood clots in the duodenum. A few hours later, the patient underwent a second-look UGIE that showed no mucosal defect. A DL was suspected and the patient underwent EUS, which was performed using a systematic gastric wall evaluation, showing an abnormal submucosal vessel on the posterior wall of the gastric body, close to the splenic hilum. EUS-guided sclerotherapy with $6 \mathrm{~mL}$ of polidocanol $2 \%$ was performed. The patient was discharged after 5 days, when hemodynamic, clinical, and laboratory stabilization was achieved. Twenty-four hours after hospital discharge, he was re-admitted with UGIB and, once again, the UGIE presented digested blood and clots but could not identify the bleeding source. A new EUS was performed, identifying a clot on the greater gastric curvature, in the same location as the previously treated DL. An attempt of EUS-guided hemostasis with through-the-scope clip triggered oozing bleeding, further controlled with endoscopic 15 $\mathrm{mL}$ of adrenalin and $14 \mathrm{~mL}$ of polidocanol injection and additional through-the-scope clips. After stabilization, the patient was discharged with an outpatient EUS appointment within 2 weeks to confirm vessel obliteration. However, 10 days after hospital discharge, the bleeding recurred with associated hemodynamic instability. UGIE displayed a visible vessel, without any of the previously placed clips in situ. Endoscopic hemostasis was achieved with $13 \mathrm{~mL}$ of adrenalin and $3 \mathrm{~mL}$ of polidocanol injection plus clips. The follow-up EUS still identified a feeding vessel arising from the splenic artery and penetrating the gastric muscularis propria (Fig. 1), not successfully obliterated with previous endoscopic therapy. The patient was referred to interventional radiology for embolization. Selective splenic artery angiogram identified a short gastric artery ectasia and hypervascularization (Fig. 2, large arrow) as well as the previously endoscopically placed hemoclips (Fig. 2, small arrow), which allowed transcatheter arterial embolization (TAE) with micro-coils. The patient underwent EUS evaluation 1 month after TAE that documented successful vessel obliteration.

After 3 years free of bleeding manifestations, the patient presented with another episode of UGIB with hemodynamic instability. UGIE identified a small depressed area with a pulsatile, nonactively bleeding vessel, in the medial part of the gastric body anterior wall - a new DL location. Since the patient was hemodynamically unstable, this area was marked with a hemoclip, and CT angiography was performed in attempt to locate and possibly treat the source of bleeding. However, this method showed no active bleeding source. EUS revealed a feeding vessel, correspond- 


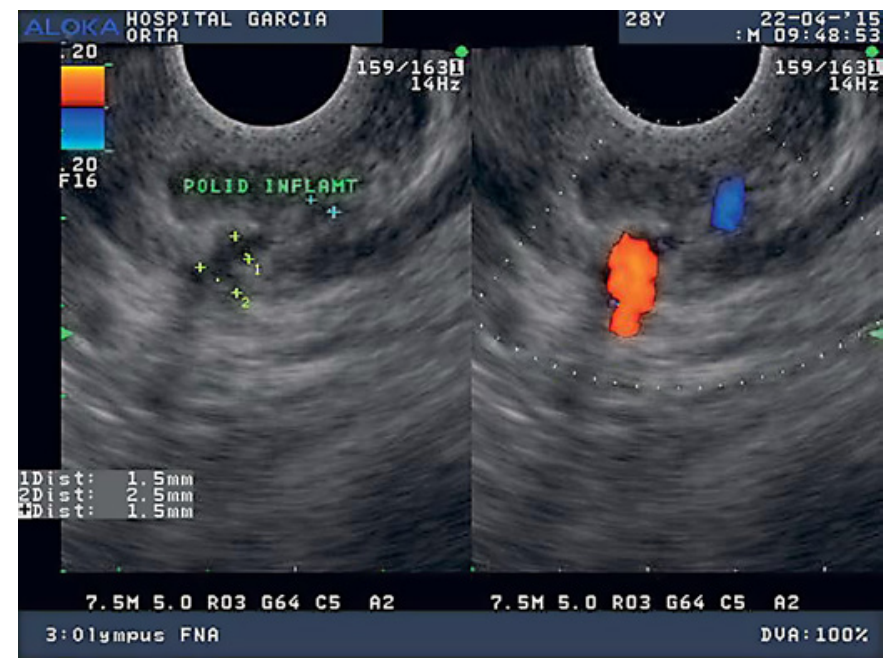

Fig. 1. Endoscopic ultrasonography showing feeding vessel arising from the splenic artery, penetrating the gastric muscularis propria (Dieulafoy's lesion).

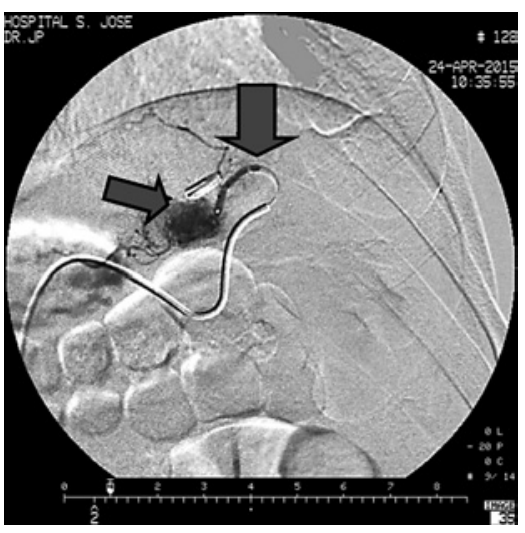

Fig. 2. Selective splenic artery angiogram showing a short gastric ectasia and hypervascularization (large arrow) as well as hemoclips (small arrow).
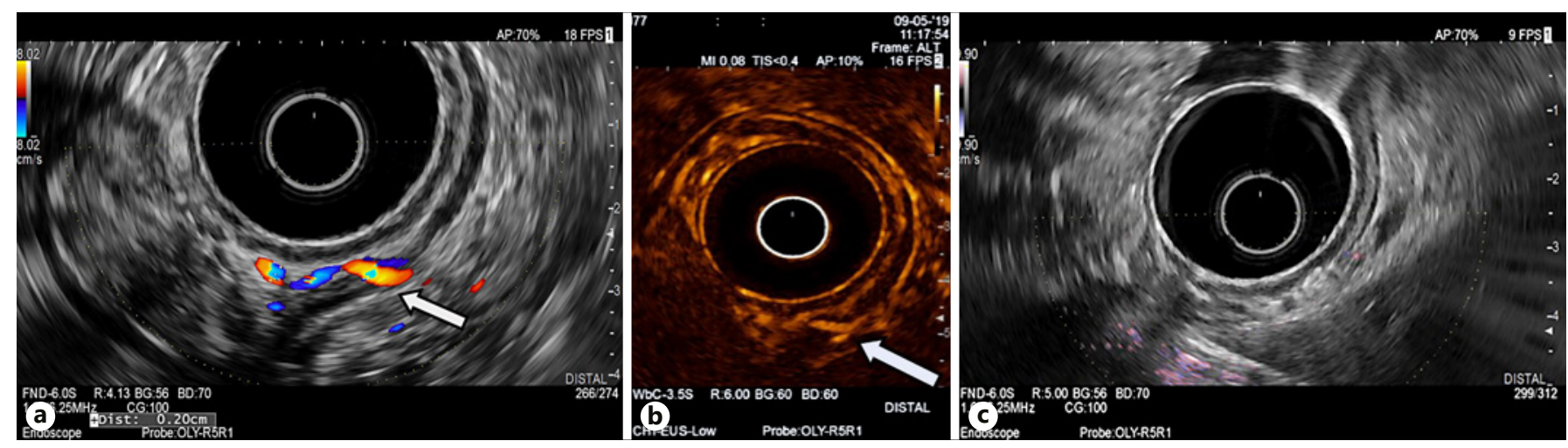

Fig. 3. a Endoscopic ultrasonography (EUS) revealing a feeding vessel (second Dieulafoy's lesion) arising from the left gastric artery. b Feeding vessel visible with SonoVue. c EUS confirming obliteration of the previously treated Dieulafoy's lesion.

ing to a second DL, arising from the left gastric artery (Fig. 3a, b) while confirming obliteration of the previously treated lesion (Fig. 3c). The patient underwent selective left gastric artery angiogram, with identification of an abnormal vessel adjacent to the clip, and TAE could be performed (Fig. 4). The patient has evolved favorably with no further episodes of GI bleeding.

\section{Discussion/Conclusion}

$\mathrm{DL}$ is a dilated aberrant submucosal vessel that does not undergo normal branching, unlike normal vessels which become progressively smaller when penetrating the GI wall. This results in a submucosal vessel with a large caliber (about 10 times the normal caliber of muco- sal capillaries), despite its superficial location in the GI wall [10]. When this vessel erodes the overlying epithelium, in the absence of a primary ulcer, it typically produces severe acute onset bleeding without prior symptoms and often causes hemodynamic instability and requires several blood transfusions.

$\mathrm{DL}$ is a rare cause of GI bleeding. There are only 2 reported cases in the literature of life-threatening UGIB caused by two synchronous DL, one case with DL in the stomach and jejunum [11] and another with two gastric DL [12]. To the best of our knowledge, there are no reported cases of two metachronous DL.

UGIE is the first diagnostic approach recommended for detecting DL, and it is particularly helpful during ac- 
Fig. 4. a Selective left gastric artery angiogram, with identification of abnormal vessel (second Dieulafoy's lesion) adjacent to the hemoclip. b Angiogram after transcatheter arterial embolization.
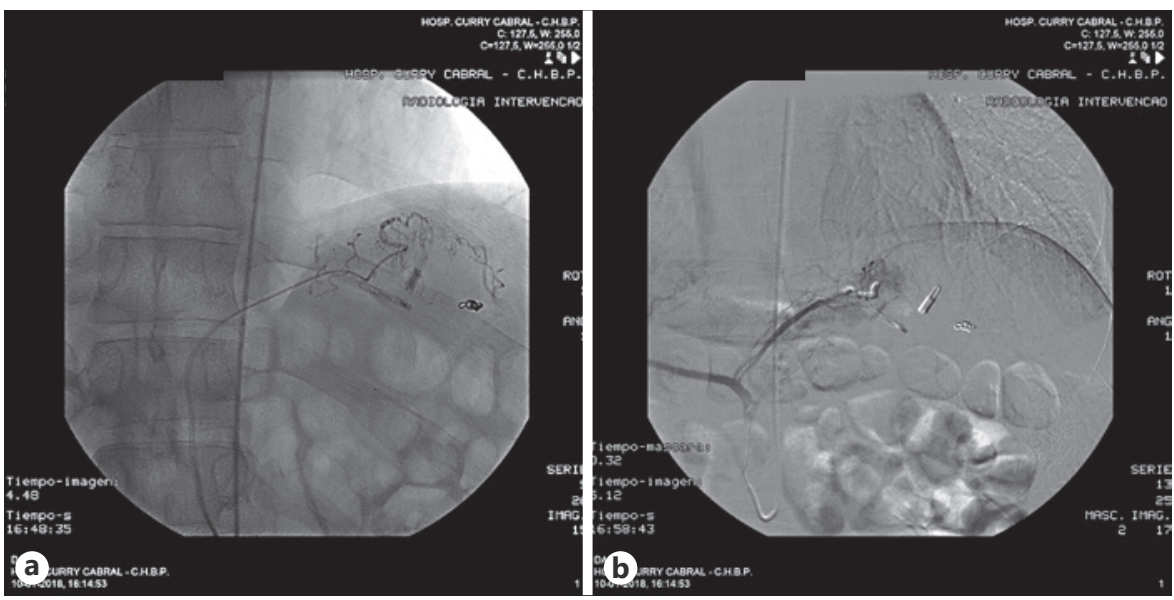

tive bleeding $[7,13]$. In this scenario, arterial pumping may be visualized in an area without a clear visible ulcer. In the absence of active bleeding, a DL may appear as a raised nipple or visible vessel. Nevertheless, UGIE is only diagnostic in $70 \%$ of the patients. In up to $30 \%$, these lesions may be missed due to small size, intermittent bleeding, location between gastric folds or under gastric contents, or adherent clot [5].

EUS is a technique that has proven to be useful to confirm the diagnosis in patients with suspected UGIB caused by DL $[6,7]$. Typical EUS features include an abnormally large, 2- to 3-mm caliber, pulsatile, high-flow submucosal artery, usually located along the lesser gastric curvature near the gastroesophageal junction. In the present case, EUS was extremely important for diagnosing the UGIB etiology. In our hospital, it is common practice to perform EUS in cases of severe UGIB, clinically suggestive of a possible DL, after an inconclusive UGIE manifested as hematemesis. A systematic and thorough gastric evaluation performed by an experienced EUS operator is mandatory for optimizing detection of a possible DL. In this patient, the systematic assessment of the gastric vasculature by EUS allowed the diagnosis of DL after a single UGIB episode.

Several approaches for endoscopic hemostasis have been shown to be effective for DL, including a combination of epinephrine injection followed by bipolar probe coagulation, heater probe thermal coagulation, argon plasma coagulation, through-the-scope or over-the-scope clip placement, band ligation, and cyanoacrylate injection [3, 14-17]. EUS has also evolved to guide treatment of GI bleeding caused by DL, mainly in a nonactive bleeding setting. It may also be used to guide other nonendoscopic techniques, such as interventional radiologic therapy [9], through marking the blood vessel location. There are several EUS-guided procedures that can be used to treat DL, including adren- alin, polidocanol, or cyanoacrylate injection. EUS also allows lesion marking with a subepithelial tattoo or clip to direct further endoscopic hemostasis in cases of rebleeding [9]. After a first endoscopic treatment session, additional options include repeating endoscopic hemostasis, attempting EUS-guided therapy, angiographic embolization, or surgical wedge resection of the lesion. This patient presented recurrent episodes of UGIB despite multiple endoscopic and EUS-guided hemostasis, ultimately requiring radiologic intervention. The metallic clips used to mark the lesion site and placed with EUS guidance helped in directing endovascular intervention, emphasizing the important role of EUS in the management of DL.

Finally, additional benefits of EUS include the ability to confirm the efficacy of endoscopic hemostasis of a bleeding DL by demonstrating absent Doppler flow after therapy [6]. In our institution, we also routinely perform EUS after endoscopic hemostasis to confirm vessel obliteration [18]. This patient underwent several EUS in the follow-up, which documented successful obliteration of the first treated DL.

In conclusion, the authors report a unique case of severe, recurrent UGIB caused by two metachronous gastric DL in the same, otherwise healthy, young patient. This case report emphasizes the value of a systematic EUS evaluation of the GI wall if a DL is suspected. In addition, we acknowledge the outstanding role of EUS in the treatment and follow-up of these lesions, as well as in association with other techniques, such as TAE.

\section{Statement of Ethics}

This study did not require informed consent or review/approval by the appropriate ethics committee. 


\section{Conflict of Interest Statement}

In this paper, the authors used two images previously published in a snapshot in GE Portuguese Journal of Gastroenterology [19]. The EUS images were obtained by the same echoendoscopist in our center. Regarding the angiogram image, we obtained consent from the radiologist. The authors have no other conflicts of interest to declare.

\section{Funding Sources}

The authors have no funding sources regarding the present manuscript.

\section{Author Contributions}

Mariana Brito wrote the manuscript. All authors were involved in the case management, manuscript organization, and revising the text.

\section{References}

1 Veldhuyzen van Zanten SJ, Bartelsman JF, Schipper ME, Tytgat GN. Recurrent massive haematemesis from Dieulafoy vascular malformations-a review of 101 cases. Gut. 1986 Feb;27(2):213-22.

2 Stark ME, Gostout CJ, Balm RK. Clinical features and endoscopic management of Dieulafoy's disease. Gastrointest Endosc. 1992 SepOct;38(5):545-50.

3 Dulic-Lakovic E, Dulic M, Hubner D, Fuchssteiner H, Pachofszky T, Stadler B, et al.; Austrian Dieulafoy-bleeding Study Group. Bleeding Dieulafoy lesions of the small bowel: a systematic study on the epidemiology and efficacy of enteroscopic treatment. Gastrointest Endosc. 2011 Sep;74(3):573-80.

4 Nojkov B, Cappell MS. Gastrointestinal bleeding from Dieulafoy's lesion: clinical presentation, endoscopic findings, and endoscopic therapy. World J Gastrointest Endosc. 2015 Apr;7(4):295-307.

5 Chung YF, Wong WK, Soo KC. Diagnostic failures in endoscopy for acute upper gastrointestinal haemorrhage. Br J Surg. 2000 May; 87(5):614-7.

6 Jaspersen D. Dieulafoy's disease controlled by Doppler ultrasound endoscopic treatment Gut. 1993 Jun;34(6):857-8.
7 Squillace SJ, Johnson DA, Sanowski RA. The endosonographic appearance of a Dieulafoy's lesion. Am J Gastroenterol. 1994 Feb;89(2): 276-7.

8 Wong Kee Song LM, Banerjee S, Barth BA, Bhat Y, Desilets D, Gottlieb KT, et al.; ASGE Technology Committee. Emerging technologies for endoscopic hemostasis. Gastrointest Endosc. 2012 May;75(5):933-7.

9 Law R, Fujii-Lau L, Wong Kee Song LM, Gostout CJ, Kamath PS, Abu Dayyeh BK, Gleeson FC, Rajan E, Topazian MD, Levy MJ. Efficacy of endoscopic ultrasound-guided hemostatic interventions for resistant nonvariceal bleeding. Clin Gastroenterol Hepatol. 2015 Apr; 13(4):808-12.e1.

10 Lee YT, Walmsley RS, Leong RW, Sung JJ. Dieulafoy's lesion. Gastrointest Endosc. 2003 Aug;58(2):236-43.

11 Marangoni G, Cresswell AB, Faraj W, Shaikh $\mathrm{H}$, Bowles MJ. An uncommon cause of lifethreatening gastrointestinal bleeding: 2 synchronous Dieulafoy lesions. J Pediatr Surg. 2009 Feb;44(2):441-3.

12 Turner JD, Bavakunji RV, Selby NM. A rare cause of massive upper gastrointestinal bleeding in a dialysis patient: synchronous Dieulafoy lesions. NDT Plus. 2010 Dec;3(6):594-5.

13 Kaufman Z, Liverant S, Shiptz B, Dinbar A Massive gastrointestinal bleeding caused by Dieulafoy's lesion. Am Surg. 1995 May;61(5): 453-5.
14 Chen YY, Su WW, Soon MS, Yen HH. Delayed fatal hemorrhage after endoscopic band ligation for gastric Dieulafoy's lesion. Gastrointest Endosc. 2005 Oct;62(4):630-2.

15 Yamaguchi Y, Yamato T, Katsumi N, Imao Y, Aoki K, Morita Y, et al. Short-term and longterm benefits of endoscopic hemoclip application for Dieulafoy's lesion in the upper GI tract. Gastrointest Endosc. 2003 May;57(6):653-6.

16 Matsui S, Kamisako T, Kudo M, Inoue R. Endoscopic band ligation for control of nonvariceal upper GI hemorrhage: comparison with bipolar electrocoagulation. Gastrointest Endosc. 2002 Feb;55(2):214-8.

17 Iacopini F, Petruzziello L, Marchese M, Larghi A, Spada C, Familiari P, et al. Hemostasis of Dieulafoy's lesions by argon plasma coagulation (with video). Gastrointest Endosc. 2007 Jul;66(1):20-6.

18 Pinto-Marques P, Gíria J, Brito M, Camacho R, Loureiro R. Unusual cause for upper GI bleeding: a splenic artery aneurysm mimicking a Dieulafoy lesion. Role for systematic EUS assessment? Gastrointest Endosc. 2010 Apr;71(4):845-6; discussion 847.

19 Barosa R, Pires S, Pinto-Marques P, Pereira JA, Bilhim T. Dieulafoy's Lesion: The Role of Endoscopic Ultrasonography as a Roadmap. GE Port J Gastroenterol. 2017 Mar;24(2):957. 